\title{
Cidades Universitárias, Cidades Médias, Cidades Pequenas: Análises Sobre o Processo de Instalação de Novos Campi Universitários
}

\author{
University Towns, Medium and Small-Sized Cities: \\ Analyzing the Process of Establishing \\ New University Campuses
}

\author{
Wendel Henrique Baumgartner \\ Universidade Federal da Bahia \\ Salvador, Brasil
}

\begin{abstract}
Resumo: A última década marca um período de grande expansão das universidades públicas federais em direção às cidades médias e pequenas do Brasil. Para além do significativo impacto no acesso ao ensino superior, os resultados da expansão são visíveis no espaço intraurbano em razão do forte impacto econômico, político e cultural trazido pelos campi. Tanto em áreas economicamente estagnadas quanto naquelas de forte dinamismo industrial ou do agronegócio, esses novos campi visam também ao desenvolvimento urbano e regional, a partir de aspectos ligados ao que se pode configurar como economia do conhecimento ou economia criativa. Neste texto, buscamos analisar, dentre várias possibilidades, as relações entre as universidades e as cidades médias e pequenas, tanto no ponto vista teórico quanto empírico, bem como apresentar alguns resultados de pesquisas realizadas na Bahia.
\end{abstract}

Palavras-chave: Universidades; Cidades Médias; Cidades Pequenas.

Abstract: Over the last decade new federal public universities have been built throughout Brazil,particularly in medium- and small-sized cities. In addition to providing greater access to higher education, the new campuseshave had important economic, political and cultural impacts within cities. In economically stagnant regions as well as in those of strong industrial or agribusiness dynamism, the new campuses were established with the express intent of promoting urban and regional development through the introduction of knowledge and creative economies. In this text, we analyze, among several possibilities, some of the relationships which arise between universities and medium and small-sized cities, using research results from Bahia State.

Keywords: Universities; Medium and Small-Sized Cities; Bahia.

\footnotetext{
i Professor Associado, Departamento de Geografia - IGEO/Universidade Federal da Bahia. E-mail: wendel_henrique@hotmail.com.
} 


\section{Introdução}

Ao iniciarmos este texto convém esclarecer quais são os pontos de que gostaríamos de tratar, bem como qual o caminho que optamos seguir, dentre tantas possibilidades encontradas na discussão sobre funções ou adjetivações de cidades e espaços urbanos. Nossos objetivos são: construir um pensamento, uma análise, sobre o que vem acontecendo em algumas cidades médias e pequenas do Brasil após a recente expansão das instituições públicas federais de educação superior, notadamente universidades; apresentar resultados recentes de nossas pesquisas; fomentar a discussão sobre as possibilidades de classificação/adjetivação/definição dessas cidades, do ponto de vista funcional, a partir da inserção de funções vinculadas ao ensino superior. Cabe salientar que não estamos propondo um sistema classificatório de rotulação das cidades, mas sim um debate sobre as relações entre os campi universitários e as cidades. Também reforçamos que nas próprias redes urbanas onde estão inseridas essas cidades são observadas transformações, acionadas pela diversificação dos papéis e funções das cidades, o que remete a possibilidade de análises em múltiplas escalas, partindo do espaço intraurbano até o regional.

Não nos propomos a discussão sobre intervalos de população ou de quantidade de funções que defina e classifique as cidades, bem como indiquem sua posição hierarquizada em um sistema urbano rígido e classificatório. Não se trata de negar ou desmerecer esses estudos, muito pelo contrário, partimos do pressuposto de que existe um ou vários elementos/componentes estatísticos que definem, dentro de um sistema classificatório próprio, uma cidade pequena, média ou grande.

Ainda que muito seja debatido sobre a ideia de que as cidades não devem ser definidas pelo quantitativo populacional, o contingente populacional é muitas vezes utilizado para definir quais cidades serão foco de uma ou outra política pública. No caso da expansão dos campi universitários e institutos federais esses números variam entre 500 mil e 50 mil habitantes, respectivamente, como os recortes obrigatórios a serem atendidos. Além do critério populacional definido pelo MEC (Ministério da Educação), local e regionalmente, outros elementos, entre eles a atuação de grupos políticos e movimentos sociais, participam na concorrência entre as cidades para o recebimento de um campus, como aconteceu em Santo Amaro (BA), com a atuação do movimento "Para ser do Recôncavo precisa estar em Santo Amaro". ${ }^{1}$

Outro ponto fundamental para explicitação de nossas opções neste texto é a impossibilidade de dissociarmos a teoria, a empiria e a técnica de um método. A importância desse pensamento articulado entre a teoria, a empiria e a técnica, a nosso ver, pode evitar uma teorização sobre cidades que não existem, a não ser no mundo idealizado da teoria, negando a empiria. Também podem evitar o velho temor da empiricização dos estudos (domínio do plano empírico) ou da aplicabilidade acima de tudo (tecnicismo). Cabe esclarecer que o início das reflexões presentes nesse texto origina-se de algumas bases empíricas já vividas, estudadas ou ainda em fase de estudo, como Cachoeira, Cruz das Almas, Santo Antônio de Jesus, Feira de Santana e Barreiras, na Bahia; Chapecó, em Santa Catarina; Bagé e Erechim, no Rio Grande do Sul; Rio Claro, São Carlos e Piracicaba, São Paulo; Guaxupé, Ituiutaba e Viçosa, em Minas Gerais, entre outras. Bem como de uma pesquisa de pós-doutorado ${ }^{2}$ em Passau (Alemanha) e uma pesquisa colaborativa na França (DEMAZIÉRE; BAUMGARTNER, 2015). 


\section{Cidades Universitárias, Economia do Conhecimento e Economia Criativa}

Ao pensamos a ideia de uma cidade universitária, no mundo ocidental, aparecerão alguns exemplos clássicos de imbricação, praticamente indissociáveis, entre uma cidade e sua universidade: Coimbra, Oxford, Cambridge, Bolonha, Salamanca, Heidelberg ou Louvain, entre muitas outras. Nesses exemplos, as universidades inclusive possuem em seus nomes o próprio nome da cidade e a função educacional é preponderante, do ponto de vista econômico. Essas cidades são consideradas médias em suas redes urbanas ${ }^{3}$ e os campi, geralmente, se localizam nas áreas mais centrais das cidades, seguindo um padrão "europeu" de localização.

No Brasil, o termo cidade universitária se refere notadamente a um espaço interno da cidade, um "bairro", onde está localizado o campus universitário, como a cidade universitária da USP (Universidade de São Paulo), em São Paulo, ou a cidade universitária da UFPE (Universidade Federal de Pernambuco), em Recife. Instaladas em áreas periféricas da cidade (considerando o seu momento de construção), esses campi se aproximam de uma ideia norte-americana de campus universitário. Mencionando as nomenclaturas das universidades públicas brasileiras, aquelas com sede nas capitais seguem o modelo com os nomes dos estados em que se localizam, já nos campi do interior, como aqueles localizados nos estados de Minas Gerais e Rio Grande do Sul, entre outros, as cidades emprestam seus nomes as universidades, como Pelotas ou Uberlândia. É interessante notar que o recente processo de criação de novas universidades federais atende a uma perspectiva mais regional no batismo: Recôncavo da Bahia, Vale do São Francisco, Fronteira Sul, entre outras.

Também temos exemplos de cidades com reconhecido papel universitário, como Campinas, Ouro Preto e Santa Maria, que possuem uma forte imagem nacional atraindo estudantes e professores para suas universidades, mas, diferentemente do primeiro rol de cidades citadas no exterior, a função educacional não tem predominância econômica, o que é até positivo, pois não se cria uma dependência extrema a um único tipo de função urbana. Nas cidades médias e pequenas as universidades acabam se tornando grandes empregadores, em algumas delas são as maiores fontes de emprego, e acabam possuindo orçamentos maiores do que os próprios municípios, como em Botucatu ${ }^{4}$ e Viçosa.

A perspectiva econômica sobre a influência das universidades no espaço intraurbano das cidades médias e pequenas é uma das primeiras possibilidades de análise que temos construído em nossas pesquisas. Desde os anos de 1960, primeiramente na Europa ${ }^{5}$ e nos Estados Unidos e, posteriormente, no Brasil, o Estado passa a compreender a instalação de universidades e/ou campus de instituições novas e/ou já existentes como uma estratégia de desenvolvimento urbano, e até mesmo regional, de áreas economicamente deprimidas e/ ou degradadas do ponto de vista da morfologia/qualificação do espaço urbano.

A compreensão do papel das universidades como agente da (re)estruturação urbana e econômica das cidades torna-se importante, tanto em razão do volume de recursos financeiros movimentados quanto pela modificação de dinâmicas intraurbanas (moradia, circulação, usos etc.) e do cotidiano dos moradores. A implantação de uma universidade ou campus de uma universidade pública afeta as dinâmicas urbanas e regionais de cidades médias e pequenas, dentro de uma estratégia governamental de promoção do desenvolvimento que, para além do impacto econômico direto através da geração de empregos públicos de alta qualificação e gastos básicos de alunos e professores, promove a melhoria dos padrões educacionais, qualificação da força de trabalho, avanço e

Espaço Aberto, PPGG - UFRJ, V. 5, N.1, p. 73-93, 2015 
desenvolvimento tecnológico e cultural. Essas características se relacionam com a forte influência que a educação tem na chamada "era da economia do conhecimento".

Segundo Cassiolato (1999), a ideia de economia do conhecimento, ${ }^{6}$ ou economia baseada no conhecimento, deriva do desenvolvimento de novos processos produtivos fundados mais na aplicação e desenvolvimento de novas tecnologias ou no design de produtos do que no produto propriamente dito. Há expansão e intensificação do uso do conhecimento "mais avançado" em diversos setores produtivos, dos mais tradicionais (indústria metalomecânica, química, etc.) aos mais contemporâneos (eletrônicos, informática, etc.), passando por setores como produção cultural, publicidade, entre outros. Para atender essa demanda econômica por conhecimento, as universidades atuam muitas vezes em parceria com setores produtivos, ${ }^{7}$ para o desenvolvimento de conhecimento básico e aplicado para essa demanda. No período contemporâneo, observa-se um avanço dessa relação entre as universidades e a produção/difusão do conhecimento para fins de desenvolvimento econômico, o que acaba por transformar o conhecimento em uma commodity. Continua Cassiolato (1999, p. 175) afirmando que a produção do conhecimento conecta "o sistema educacional, as universidades, os institutos de pesquisa tecnológica, os serviços de informação, assim como as atividades de P\&D das firmas e, de uma maneira mais ampla, as próprias políticas de informação e de C\&T".

Analisando um caso nos EUA, Zecher (2005) coloca que as políticas tradicionais de desenvolvimento econômico nas cidades médias americanas se baseiam na oferta de incentivos fiscais e de localização. Entretanto, esse modelo se mostrou falho e propiciou a estagnação econômica de várias cidades, com declínio da atividade industrial, perda de empregos e baixa competitividade. A solução para essa questão econômica seria a passagem de uma economia baseada em modelos tradicionais de produção e incentivo para um modelo de economia criativa e de inovação, implicando a melhoria da qualificação profissional e de infraestrutura, desenvolvendo a economia do conhecimento nessas cidades. Zecher (op. cit.) afirma ainda, após vasta pesquisa bibliográfica, que esse salto qualitativo só é alcançado através do impacto positivo das universidades e dos institutos de pesquisa tecnológica, pois esses possuem força para serem agentes desencadeadores e promotores da economia do conhecimento, tanto em nível local quanto regional.

No Brasil, a expansão de instituições de ensino superior pode ser compreendida como uma política de Estado, que visa dotar o território de equipamentos necessários para a participação nas atividades produtivas mais avançadas. Uma das demandas produtivas colocadas por setores produtivos e que a expansão das universidades, institutos tecnológicos ou centros de pesquisa e desenvolvimento tenta resolver está no campo, através do melhoramento de sementes, pesquisas com animais, suporte para ampliação dos complexos agroindústrias. Assim, uma parcela das universidades no interior do Brasil acaba por se "especializar" em cursos voltados para a produção de conhecimento "agropecuário" e desenvolvimento do agronegócio.

Se em outros momentos do desenvolvimento tecnológico o acesso a informação e, principalmente, de contato com o mundo era privilégio das universidades localizadas em grandes centros, hoje, com a expansão das redes de informação (fibras óticas e satélites), autoestradas e aeroportos, essa diferenciação na dotação de infraestruturas de transporte e comunicação foi diluída. É claro que não foram completamente superadas, pois geralmente o tempo de deslocamento e as conexões, quando tratamos de transporte aéreo, por exemplo, é maior para aqueles que têm como ponto de origem e/ou destino cidades menores. 
Esta ideia segue em direção ao que Wüsten (1998) escreve quando afirma que as universidades fazem a diferença nos locais onde se localizam. É importante reconhecer que em cidades grandes a influência é minimizada pela própria dinâmica urbana das cidades, mas uma universidade maior pode dominar completamente o espaço urbano de uma cidade média ou pequena. Na grande cidade a diversificação econômica e mesmo cultural, bem como suas conexões com outras culturas, faz com que o aporte financeiro direto e indireto da universidade seja diluído por seu próprio dinamismo. Outra diferença entre universidades localizadas em cidades de diferentes portes está no fato de que a cidade grande oferece, por exemplo, mais possibilidades de permanência aos recém-formados em função da diversidade do mercado de trabalho.

Para além do aspecto econômico, as universidades têm um forte componente cultural e artístico em suas fundações. Claval (1998) destaca que as universidades foram importantes para o desenvolvimento das atividades culturais; seus professores escrevem nos jornais locais; e sua comunidade é frequentadora mais assídua de espetáculos culturais. Além disso, professores e estudantes contribuem para a criação e difusão de ideologias modernas e são apoiadores de diversos movimentos políticos e sociais. Por fim, aumentam a concentração de jovens nas cidades, favorecendo a difusão das discussões políticas, passando a ser um elemento essencial em todas as revoltas ou revoluções urbanas. O autor destaca ainda que a expansão das universidades para as cidades menores é muito incentivada pelas mesmas, em uma acirrada competição, uma vez as universidades fomentam a vinda de serviços e comércios para o centro urbano, em função de um perfil populacional de maior renda, bem como de atividades vinculadas a alta tecnologia, incentivando a constituição de polos tecnológicos.

Nesse ponto, podemos fazer outra associação entre as universidades e as cidades, através de conceitos como economia criativa ou cidade de inovação. A economia criativa é aquela produzida por setores como arquitetura, artes, cinema, publicidade, música, mídia, comunicação, informações, entre outros. Richard Florida (2002 e 2005) apresenta, nos diversos estudos sobre o papel da economia criativa e das cidades criativas (ou inovadoras),o papel das universidades tanto na criação de produtos/ideias inovadoras quanto na produção de um ambiente criativo e no fortalecimento da imagem das cidades universitárias perante as demais cidades. Infelizmente, ainda observamos nas universidades brasileiras poucos cursos voltados para a economia criativa, com exceção aos cursos publicidade. Também constatamos uma forte pressão política para a oferta de cursos "tradicionais, de prestígio", como direito, administração ou medicina, deixando pouco espaço para cursos com "menor" prestígio, mas com grande impacto na economia criativa. ${ }^{8}$

\section{A Expansão das Universidades Federais no Brasil e na Bahia}

Desde a segunda metade dos anos 2000, estamos observando a forte expansão das instituições (Universidades e Institutos Tecnológicos) federais de ensino superior, mantidas pelo Ministério da Educação. Em vários estados brasileiros, essa expansão se direciona para cidades médias e pequenas do interior, após um grande período de concentração de instituições federais apenas nas suas capitais.

Nas figuras 1 a $7^{9}$ localizamos e analisamos a expansão das universidades federais no Brasil, usando a base municipal e retratando apenas os campi que oferecem ou ofereceram cursos de graduação presenciais. 


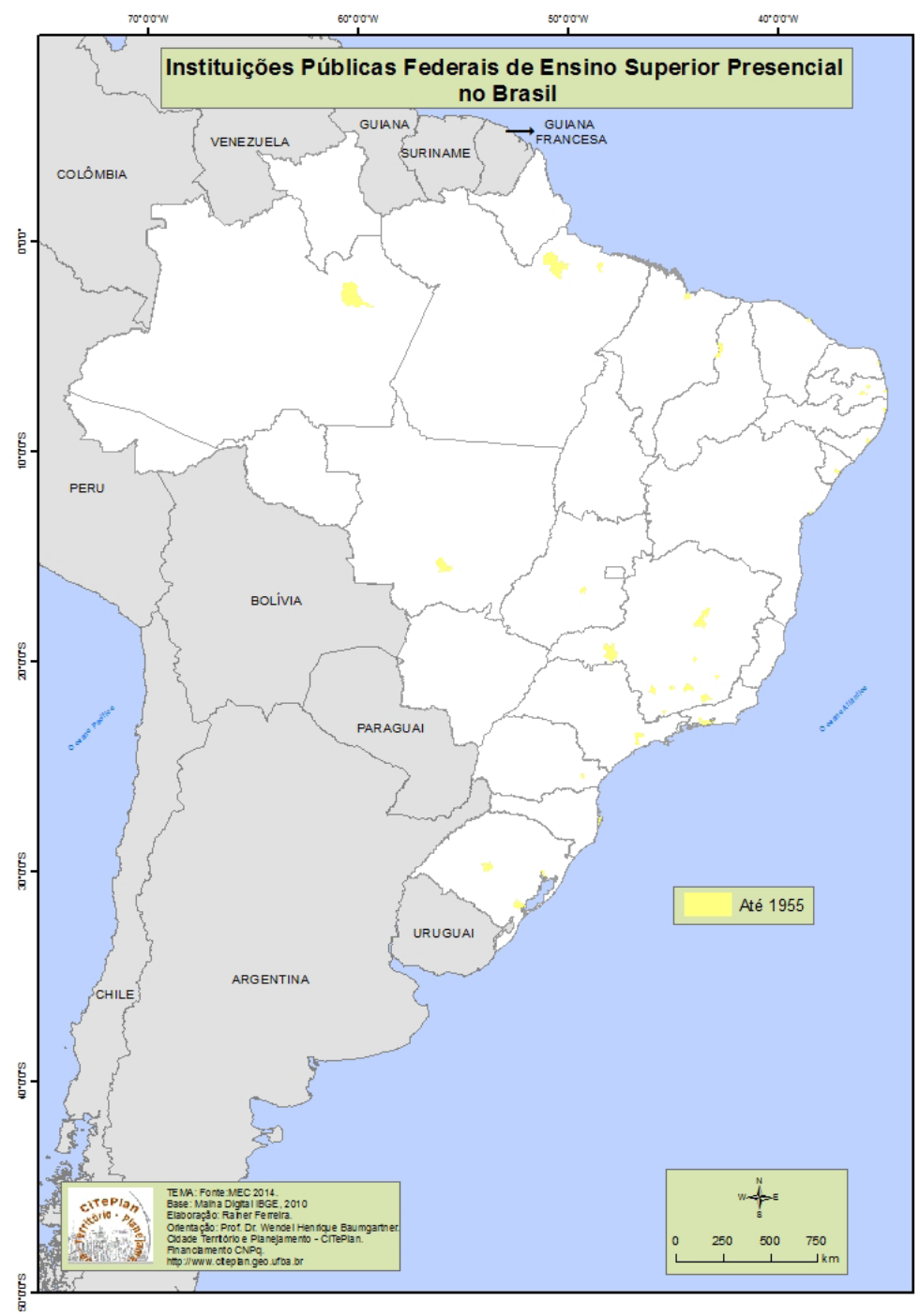

Esse primeiro período é marcado pelas primeiras instituições ligadas ao poder central no estabelecimento de curso de ensino superior, para além das instituições de cunho religioso que já ofertavam cursos de teologia e filosofia. Na virada para o século XX, apenas quatro cidades brasileiras tinhas cursos superiores financiados pelo poder central: Salvador, Recife, São Paulo e Rio de Janeiro. Nos anos 1930 começa uma primeira onda de expansão, com a criação de universidades nas capitais dos estados e no interior, notadamente de duas unidades da federação - Rio Grande do Sul e Minas Gerais.

Figura 1 - Municípios com campus de IFES - Período até 1955. 


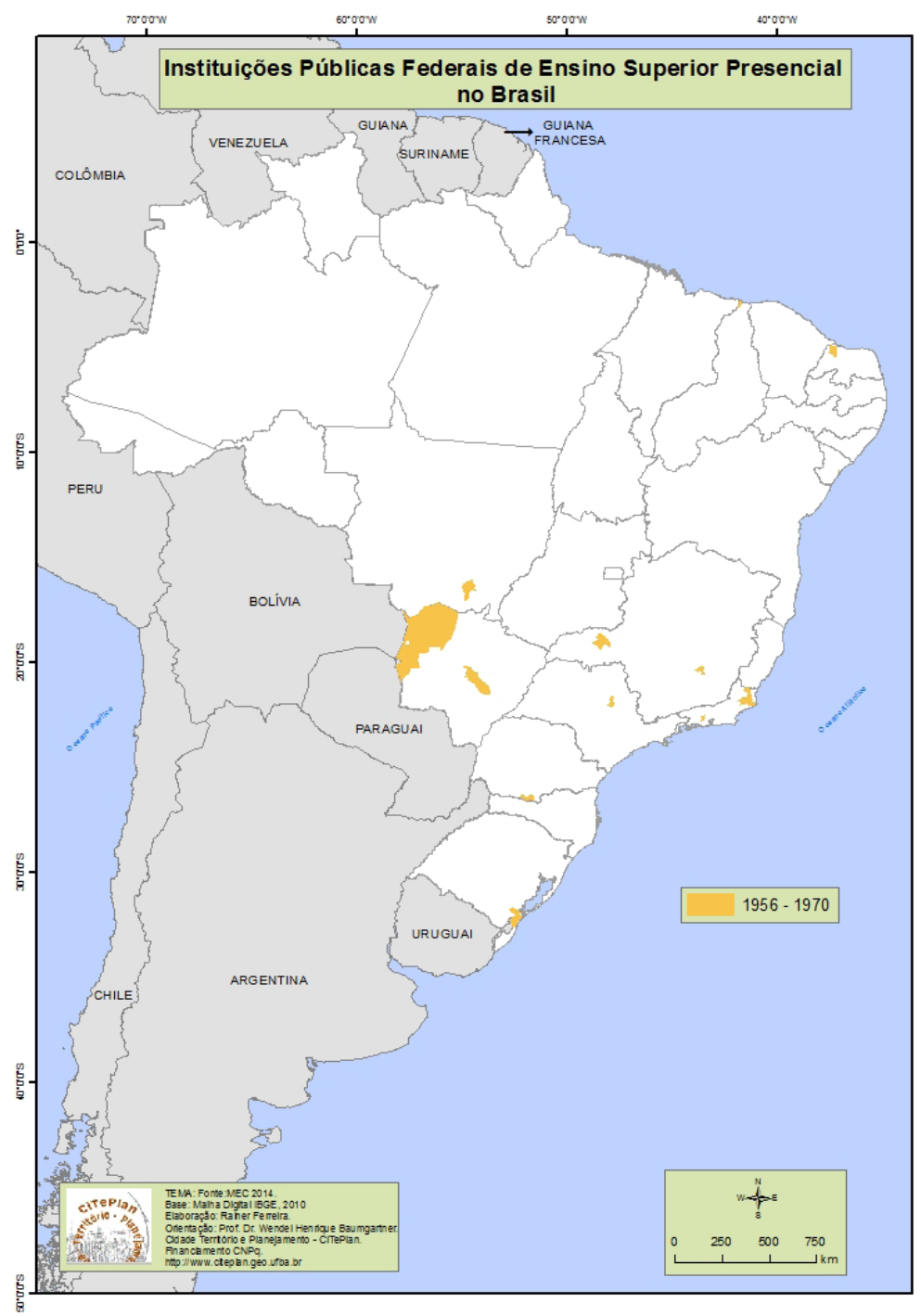

O segundo período é marcado por uma pequena expansão da rede, com destaque para uma onda em direção ao Centro-Oeste, a partir de Uberlândia até o Mato Grosso do Sul. Também destacamos a criação da UFSCar, no interior de São Paulo, onde o sistema de universidades estaduais já se interiorizava com a criação da Unicamp e Unesp.

Figura 2 - Municípios com campus de IFES - Período 1956-1970. 


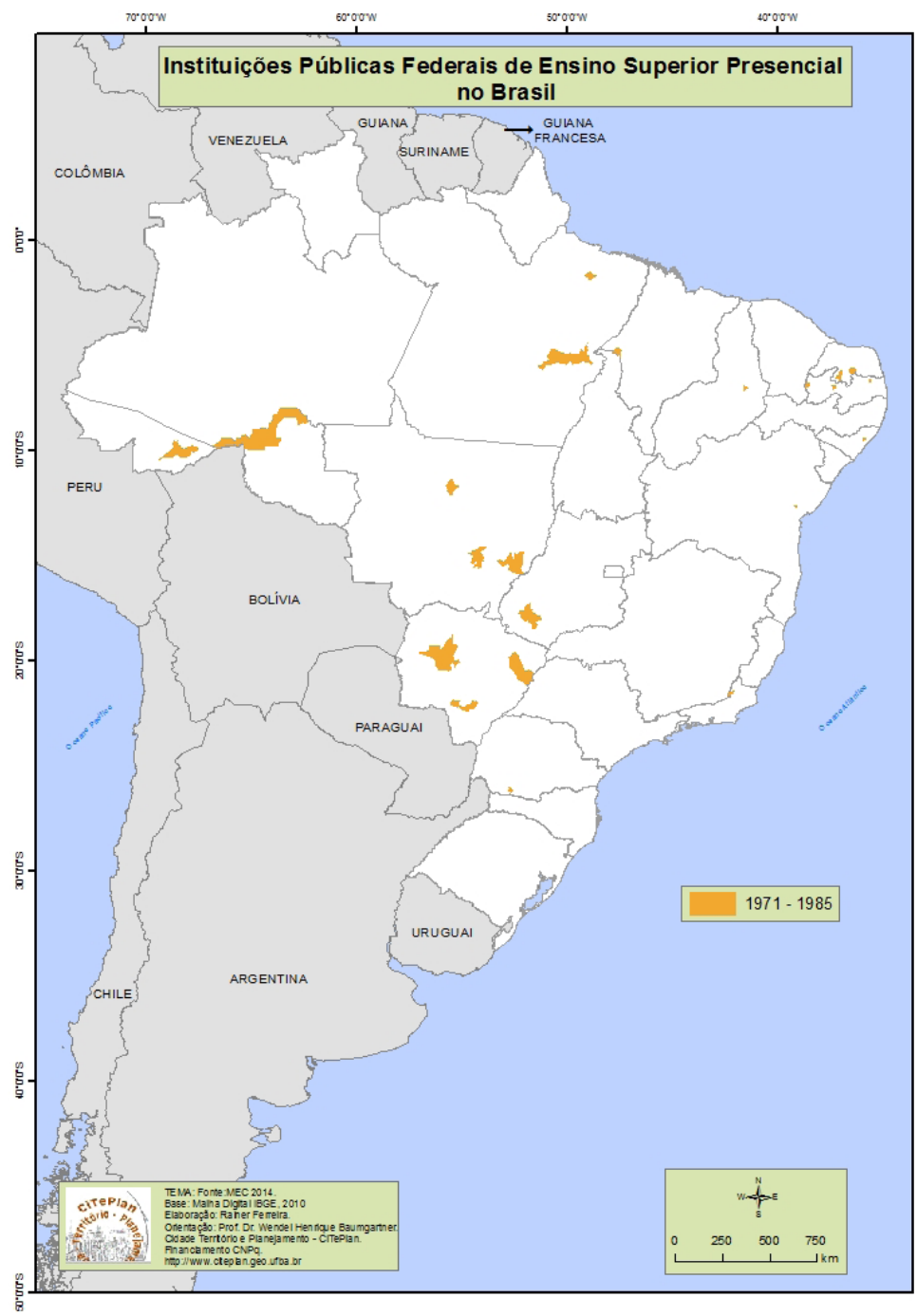

O terceiro período reforça a expansão da rede no Centro-Oeste e avança, junto a expansão da fronteira agrícola para o Norte. São criadas algumas unidades em outras regiões também vinculadas aos campi avançados de instituições já existentes, destinados, prioritariamente, às áreas de ciências agrárias.

Figura 3 - Municípios com campus de IFES -Período 1971-1985. 


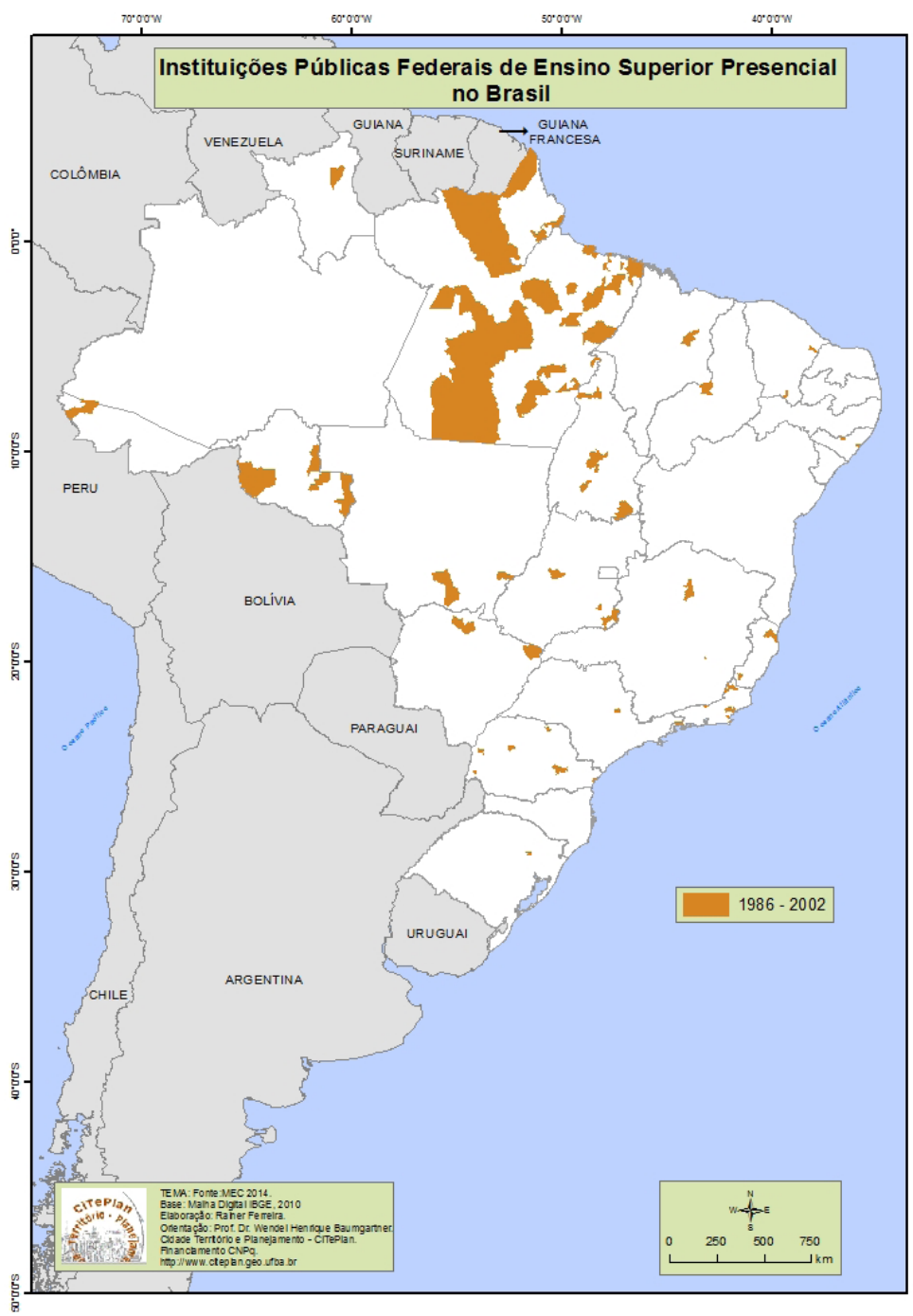

O quarto período, que marca o início da redemocratização do país, é claramente marcado pelo reforço da rede federal no Norte, com destaque para o Pará e o Amapá. Também são criadas as instituições do estado de Tocantins. Cabe mencionar que nesse período ocorre uma grande expansão das redes privadas de ensino superior.

Figura 4 - Municípios com campus de IFES - Período 1986-2002. 


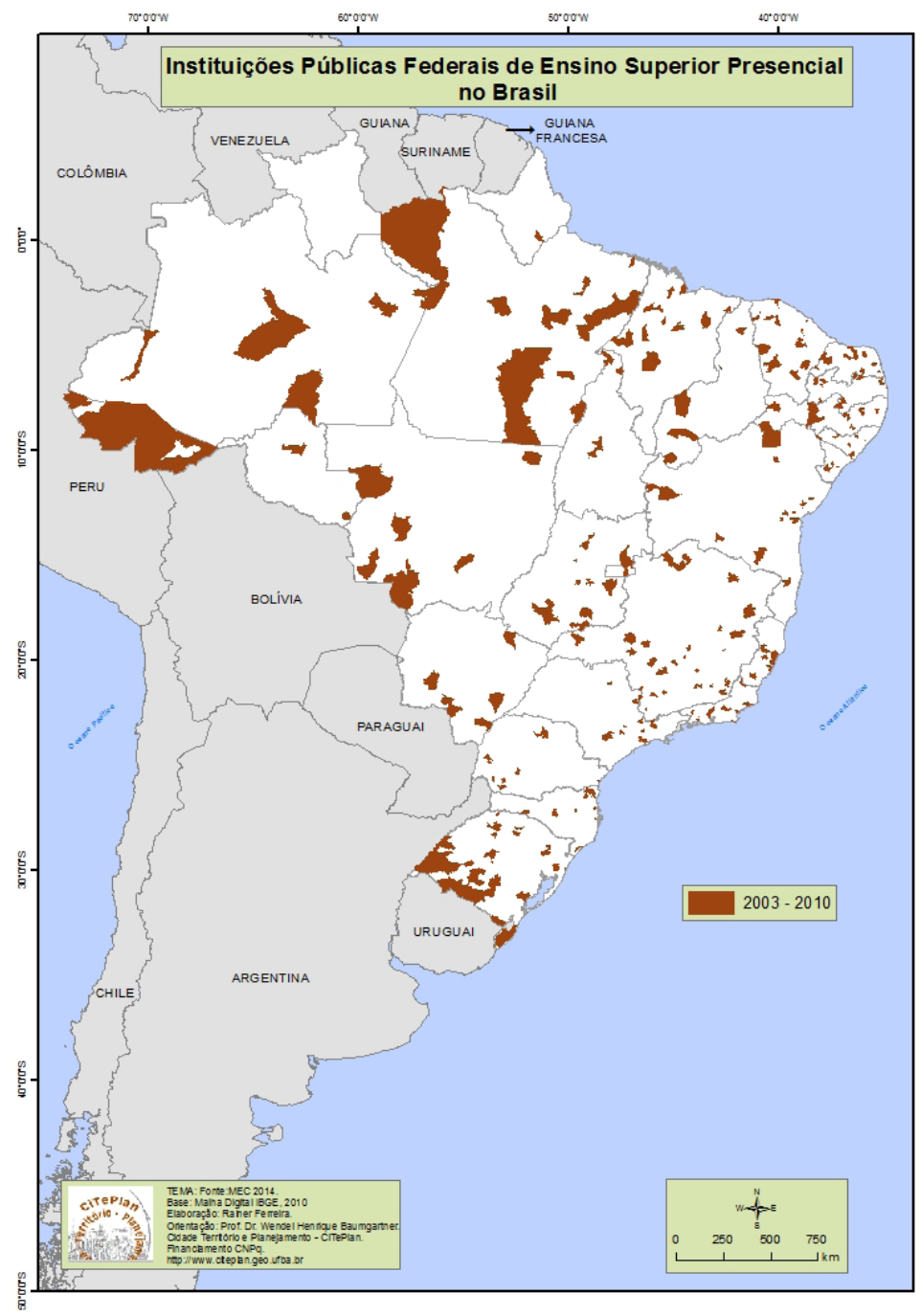

Esse é o período mais forte e balanceado, em relação a distribuição regional, da expansão da rede federal. Todos os estados receberam campi de instituições existentes ou novas. A expansão toma lugar efetivo no interior do país, sempre em uma estrutura multicampi. Há uma perspectiva mais regional na sua atuação, inclusive na nomenclatura: Universidade dos Vales do Jequitinhonha e Mucuri, do São Francisco, dos Pampas, da Fronteira Sul, entre outras. Destacamos também as IES com uma "vocação" internacional, como da Integração Latino-Americana (UNILA) e da Integração Internacional da Lusofonia Afro-Brasileira (UNILAB).

Figura 5 - Municípios com campus de IFES - Período 2003-2010. 


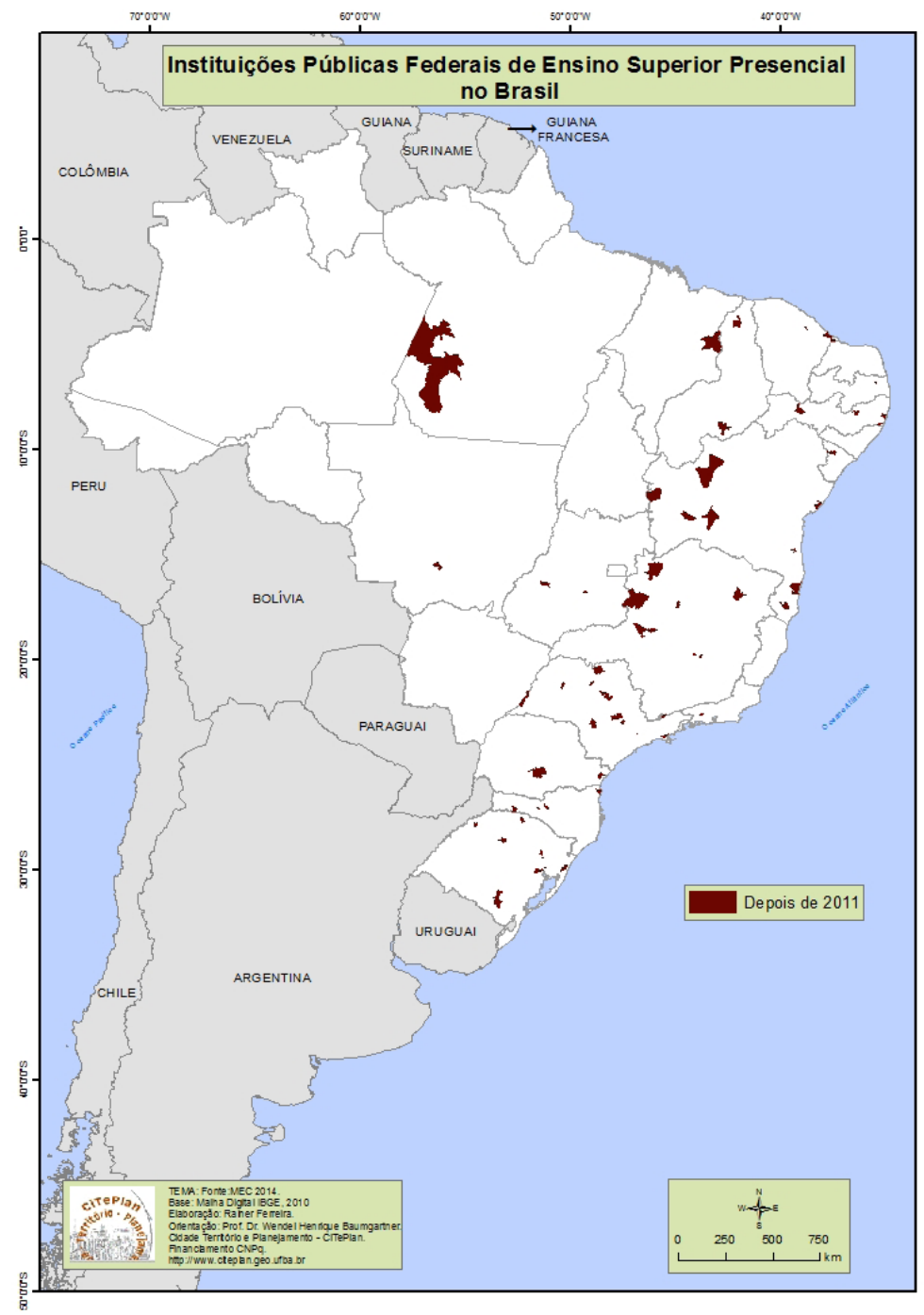

O período mais recente mostra que a expansão já está menos acelerada, em relação às universidades. O destaque é para a criação de universidades novas na área do cerrado. As novas instituições também seguem a estrutura multicampi e se localizam, de maneira geral, em áreas dinâmicas das economias regionais.

Figura 6 - Municípios com campus de IFES - Período após 2011. 


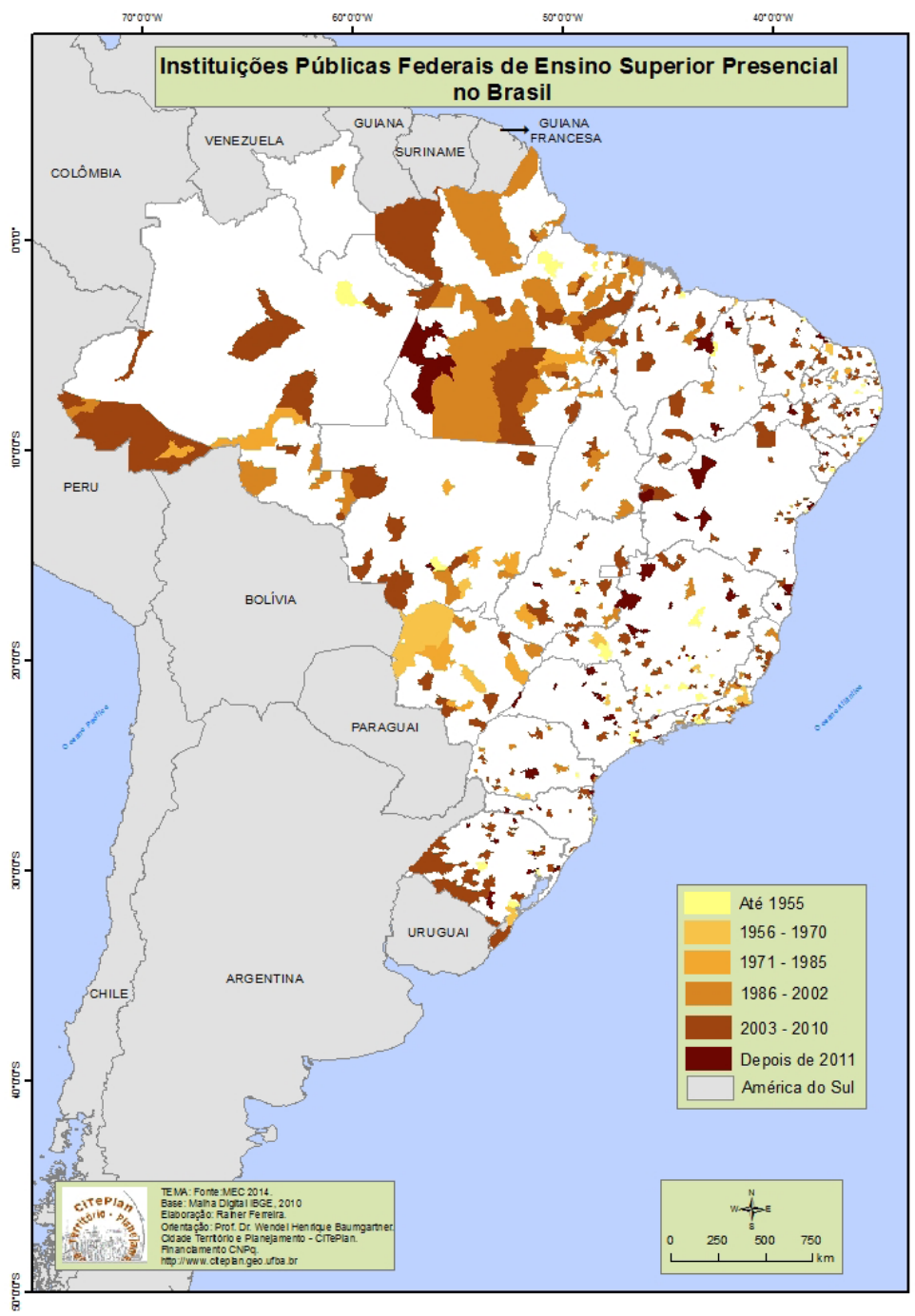

Figura 7 - Municípios com campus de IFES Síntese da expansão das Universidades Federais.

Na Bahia

Em 1808, Salvador recebeu a primeira instituição pública de ensino superior do Brasil (Faculdade de Medicina da Bahia), quando a família real portuguesa abandona Lisboa. De 1808 até 1976, apenas a cidade de Salvador possuía uma instituição pública de ensino superior vinculada ao governo central em toda Bahia. Em 1977, a Universidade Federal da Bahia (UFBA) abriu um campus em Cruz das Almas, no interior, onde foram 
implantados os cursos relacionados a agronomia. Entre 2002 e 2010, sete outras cidades receberam campus de instituições federais. Entre 2011 e julho de 2014,nove cidades entraram para esse grupo. Em 2015, quatro novos municípios do oeste do estado receberam campi. Cabe mencionar que outras cidades baianas possuem campus de instituições públicas estaduais de educação superior.

Nesse novo momento de ação direta do Estado na expansão das instituições públicas de ensino superior para cidades médias e pequenas, também se constata um rápido avanço na criação de polos que dão suporte para os cursos na modalidade de Ensino a Distância (EAD), mas esse não é o foco da nossa pesquisa.

A expansão das universidades federais de ensino superior presencial, no caso baiano, corresponde a dois processos diferentes:

a) Campus relacionado ao projeto de expansão de uma universidade existente (Campus de Barreiras e Vitória da Conquista, no caso da UFBA);

b) Campus de uma universidade completamente nova (Universidade Federal do Recôncavo da Bahia - UFRB, Universidade Federal do Oeste da Bahia - UFOB, Universidade Federal do Sul da Bahia - UFSB).

As duas situações suportam diferentes critérios de análise e possíveis diferenças na constituição do campus, quer seja de uma universidade em expansão ou de uma universidade nova, principalmente no tocante a quantidade e tipologia dos cursos a serem oferecidos, o que cria uma demanda diferencial por parte dos docentes e discentes por moradia. Pesquisas prévias (HENRIQUE, 2009, 2012 e 2013; BAUMGARTNER, 2014) indicam que professores vinculados a cursos como medicina e direito geralmente atuam em mais de uma instituição e/ou clínica/escritório; estudantes de cursos de engenharia, medicina e direito tendem a possuir uma renda média maior do que alunos dos cursos de licenciatura. Como as universidades já estabelecidas oferecem os cursos de maior "status" em seus campi-sede, no momento da expansão buscam criar cursos novos e notadamente licenciaturas. Já nas universidades novas são criados cursos de todas as áreas, inclusive estes tradicionalmente preenchidos por estudantes de maior renda.

Em 2005, a expansão da UFBA possibilitou a abertura de dois campi avançados da universidade, o Instituto Multidisciplinar de Saúde em Vitória da Conquista e o Instituto de Ciências Ambientais e Desenvolvimento Sustentável (ICADS) em Barreiras. O campus de Barreiras foi criado com mais cursos de graduação e já possuía cursos de pós-graduação quando foi desmembrado da UFBA, dando origem a outra universidade, a UFOB. Com a criação da UFOB, outras quatro cidades receberam campi da universidade: Luís Eduardo Magalhães, Barra, Santa Maria da Vitória e Bom Jesus da Lapa.

A UFRB foi criada em 2005, a partir do desmembramento de uma unidade da UFBA localizada em Cruz das Almas. Sua instalação ocorreu em 2006 em quatro municípios baianos: Cachoeira, Cruz das Almas (Reitoria), Amargosa e Santo Antônio de Jesus. Em 2014 foram implantados mais dois campi da UFRB, em Santo Amaro e Feira de Santana.

A mais recente instituição com sede no estado da Bahia é a UFSB - Universidade Federal do Sul da Bahia, que possui campi instalados em Teixeira de Freitas, Porto Seguro e Itabuna (Reitoria), além de contar com unidades auxiliares em diversos outros municípios do sul da Bahia, atendendo a um desenho curricular e institucional mais 
descentralizado que as demais instituições. Os cursos oferecidos também se distinguem dos demais, como as Licenciaturas Interdisciplinares. Algumas cidades baianas também possuem campus de instituições federais com sede em outros estados, como: Juazeiro, Senhor do Bonfim e Paulo Afonso (Universidade Federal do Vale do São Francisco - UNIVASF) e São Francisco do Conde (Universidade da Integração Internacional da Lusofonia Afro-Brasileira - UNILAB).

Essa expansão, além de possibilitar maior acesso à educação superior, tem alterado significativamente a estrutura urbana (conteúdo) e a própria morfologia das cidades (forma) que recebem esses novos campi e os polos. No plano morfológico, que segundo Capel (2002) compreende os elementos básicos que constituem a estrutura material da cidade e é produzido nas esferas sociais, econômicas, políticas e sociais, a (re)estruturação das cidades (SPOSITO, 2004) está vinculada à expansão da mancha urbana, à construções de conjuntos residenciais para estudantes, à abertura de novas vias de circulação e ao adensamento de áreas edificadas, por exemplo. No plano dos conteúdos são inseridas novas funções, ligadas à Educação, bem como novos comércios e serviços direcionados aos novos moradores que chegam a essas cidades - professores e estudantes universitários. O espaço construído (plano morfológico) e o espaço usado e apropriado (plano dos conteúdos) não estão em situações ou níveis dicotômicos, hierárquicos ou complementares. São, em realidade, duas categorias que sobrepostas, concomitantes e dialéticas participam da produção do espaço ${ }^{10}$ e que pautam nossas pesquisas e análises. ${ }^{11}$

As cidades recebem grandes investimentos que trazem consigo um incremento da migração de pessoas com alta qualificação profissional (professores universitários, pesquisadores, técnicos e administradores, entre outros), bem como estudantes universitários, muitos deles com alto poder aquisitivo, vinculados notadamente a determinados cursos $^{12}$, tais como, medicina, odontologia, engenharias e direito, entre outros. Os alunos com rendas menores, que não são atendidos pelos programas de moradia estudantil, também irão provocar um impacto no mercado imobiliário das cidades através da criação das moradias coletivas, denominadas por 'repúblicas'.

Entretanto, muitos planos diretores municipais e planos de criação/implementação dos campi universitários não tratam deste impacto imediato nas cidades. O aumento da demanda por habitação leva, primeiramente, a um aumento dos valores dos aluguéis e dos imóveis, uma vez que a oferta e o estoque habitacional nas cidades médias são pequenos. Algumas empresas, com maior capitalização, passam a construir rapidamente novas moradias, a partir das quais se observa uma proliferação daquelas localizadas em condomínios ou loteamentos, irregularmente fechados, inserindo esta nova possibilidade de moradia em muitas cidades.

No mercado imobiliário, os desejos e necessidades se espacializam nos condomínios horizontais e verticais, criando espaços de ficções e ilusões, muitas vezes frustradas em relação às representações (propagandas) que foram compradas, mas que continuam a movimentar os egos, as vaidades e os bolsos dos compradores. Muitas empresas buscam desenvolver e construir produtos específicos para este nicho de mercado que é atraído pelas amenidades, localização e possibilidades de financiamento do imóvel. Outro processo perceptível é a transferência da população local, muitas vezes de menor renda, 
para áreas periféricas, "liberando" habitações em áreas centrais e de melhor infraestrutura para os novos moradores, conforme demonstrado em nossas pesquisas de campo.

É interessante notar que esse novo perfil de moradores, contrasta com o tipo "clássico" do morador do interior. Segundo Santos (2005), as pequenas cidades do interior eram "cidades dos notáveis", povoadas por personalidades marcantes como o padre, a professora primária e o juiz. Entretanto, através da ação direta do Estado em projetos de desenvolvimento que visam não só a modernização da estrutura econômica, mas também das estruturas urbana e social, algumas cidades acabam por se transformar em "cidades econômicas", com a substituição do personalismo pela qualificação profissional. A professora primária sede lugar para a professora universitária, entram em cena o engenheiro, o agrônomo. Em nossos estudos, as novas cidades universitárias mudam de valor e os seus próprios valores, pois adquirem "condições de exercer uma função que os outros não dispõem e, através deste fato, ganha uma exclusividade" (SANTOS, 2005, p. 66).

Esses processos tornam premente uma mudança na perspectiva de compreensão da rede urbana, com destaque para os novos papéis das cidades que, independentemente de seu porte ou contingente populacional, passam a contar com formas-conteúdo e com as funções exclusivas e novas, que anteriormente não seriam imaginadas nessas localidades. Assim, constamos modificações no desenho das redes urbanas e nas áreas de influência, cada vez mais complexas e diferenciadas.

\section{Os Impactos Econômicos no Espaço Intraurbano}

Para compreensão do impacto da universidade nas cidades, entrevistamos moradores locais; membros da comunidade universitária (professores, gestores, funcionários e estudantes) residentes ou não no local; gestores e políticos, proprietários ou gerentes de empresas/indústrias que se instalaram na cidade e/ou região em função do campus e comerciantes/prestadores de serviços que possuem relações diretas e/ou indiretas com as funções da universidade, tais como proprietários de centros de fotocópias, cafés, restaurantes, livrarias e bares, entre outros. Os estudos empíricos mais detalhados foram realizados em Cachoeira, Santo Antônio de Jesus e Cruz das Almas (UFRB) e Barreiras (UFOB).

Os professores universitários, com uma renda média muito superior a da população local, indiretamente influenciam uma supervalorização de alguns espaços internos específicos das cidades, não só em função do nível de renda maior, mas também do perfil de consumo que se estabelece. Em Cachoeira, ${ }^{13}$ a renda média mensal (PNUD, 2013) per capita nos domicílios urbanos é de $\mathrm{R} \$ 368,12$. O salário (2014) de um professor com dedicação exclusiva que possua doutorado é de $\mathrm{R} \$$ 9.536,00 e de $\mathrm{R}$ \$ 8.480,00 para aqueles que possuem mestrado. Na comparação entre o salário dos professores e a renda média per capita em Cachoeira, os professores da UFRB, com mestrado ou doutorado, possuem, respectivamente, renda 23 e 25 vezes maiores que a renda média da população local. Essa diferenciação na renda teve um primeiro impacto no mercado imobiliário da cidade, com o aumento expressivo dos valores cobrados para aquisição e aluguel de imóveis. Em 2008 (HENRIQUE, 2009), o valor médio das pequenas casas (com um quarto) alugadas passou de $R \$ 150,00$, antes da chegada da UFRB, para $R$ \$ 800,00. Com essa 
valorização provocada pelo aumento da demanda e pouca oferta, a população local foi forçada a sair das áreas mais centrais da cidade e ocupar espaços periféricos.

Além do aporte em salários, é preciso mencionar os investimentos iniciais em infraestrutura, construção e recuperação de imóveis. Entre 2005-2010, os investimentos iniciais em infraestrutura da UFRB foram de aproximadamente R\$ 24 milhões, acrescidos de mais R\$ 9 milhões vinculados ao Programa Monumenta, do Ministério da Cultura, que recuperou imóveis históricos em Cachoeira.

Além do orçamento das instituições diretamente investido nas cidades, as economias locais recebem grande parcela dos salários dos funcionários técnico-administrativos e professores, bem como dos dispêndios dos estudantes para manutenção, principalmente quando suas famílias não residem nas cidades. Nas cidades do Recôncavo da Bahia, Santana (2012) coloca que o gasto médio dos alunos da UFRB é de aproximadamente R\$ 500,00 mensais. Se multiplicarmos este valor médio pelo número de alunos matriculados, temos um gasto direto da ordem de R\$3.181.000,00 no ano letivo nas cidades onde seus campi estão implantados.

De acordo com a UFRB (Boletim Informativo, 2012) a universidade contava com 6362 alunos matriculados, 36 cursos de graduação, 501 funcionários técnicos-administrativos e 519 professores (269 doutores). Em 2012, o orçamento (sem considerar salários) foi de R\$131 milhões e o custo por aluno era de R\$14 mil. Estudos indicam que apenas o Centro de Artes, Humanidades e Letras (CAHL/Cachoeira) aplica em salários líquidos (após descontos de impostos) de professores e funcionários algo em torno de R\$ 12 milhões por ano. Ainda em Cachoeira, temos um aporte médio direto, por parte dos 1511 alunos (2012) de R\$755.500,00 por mês ou R\$ 6.799.500,00 por ano letivo (9 meses). O aporte destes dois grupos (empregados - professores e técnicos - e alunos) gira em torno de R\$ 18.799.500,00 por ano.

Em Barreiras, o dado obtido em nossas pesquisas de campo em 2014, indica um gasto mensal de R\$ 321,00 por parte dos estudantes. Segundo UFOB (2015), o número de estudantes no campus de Barreiras é de 1338, o que equivaleria a um gasto direto dos alunos de R\$429.498,00 mensais, ou de R\$ 3,8 milhões em um ano letivo de aproximadamente 9 meses. Esses gastos estão voltados para moradia, lazer, transporte e estudos. O setor do comércio relacionado aos itens direto da educação (papelaria, livraria, copiadora) tem uma compreensão mais clara do impacto da UFOB na cidade. Assim como os proprietários/trabalhadores de lan-houses, bares, hotéis, lanchonetes, casas de informática, móveis e eletrodomésticos, que informam uma mudança na clientela após a chegada dos estudantes (mais jovens) e professores (maior renda), em comparação com o período anterior à instalação do campus. Se considerarmos o conjunto de professores, temos um impacto potencial mensal na economia de R\$ 1,1 milhão nas cidades-sede dos campi da UFOB (144 professores).

Detalhando alguns aspectos da influência do grupo de professores, esses informam, segundo dados da pesquisa de campo, que o elemento de mais dispêndio nas despesas mensais é a moradia, e grande parcela dos professores entrevistados mudou-se sozinho para Barreiras. Esses professores informam que a cidade é mais cara do que seus lugares de origem, sendo o aluguel apontado como muito elevado, especialmente para uma cidade do porte de Barreiras, com tão pouca oferta de serviços. Outro grupo de professores 
opta por permanecer na cidade apenas uma parte da semana, mesmo com distâncias consideráveis de seu lugar de residência. Esse grupo afirma que muitas cidades que receberam os novos campi não possuem atrativos de lazer ou infraestrutura para justificar uma mudança completa das suas residências. Na Bahia, alguns relatam deslocamentos entre Vitória da Conquista ou Barreiras até Salvador.

De maneira geral, todos os entrevistados, nas diversas cidades médias da Bahia que receberam campi universitários na última década, reconhecem a importância da política de expansão, da melhoria do acesso ao ensino superior no estado, mas também apontam problemas, tanto na infraestrutura física e tecnológica dos campi quanto das cidades. No que se refere as cidades, indicam falta de infraestrutura em geral (internet, saneamento, pavimentação, transporte), serviços melhores na área de saúde (hospitais, médicos, dentistas), equipamentos comerciais e serviços (shopping-centers) e, em muitos casos, a completa falta de equipamentos culturais, tais como teatros, cinemas, livrarias, espaços para shows.

É importante destacar que o processo de expansão das universidades federais nesse período recente completa uma década. Muitas questões problemáticas, no tocante às cidades, ainda estão em fase embrionária de resolução, mas a perspectiva é que a oferta de infraestrutura e serviços melhore e se adapte as novas funções e novas demandas da população.

\section{Considerações Finais}

A expansão das instituições superiores públicas para as cidades médias e pequenas do Brasil ainda está em andamento. Por tratar-se de um processo em construção, as análises são sempre momentâneas e visam contribuir para uma melhor compreensão do que vem se passando nessas cidades.

A implantação dos campi universitários para desenvolvimento econômico de cidade e regiões depreciadas economicamente esbarra em um problema comum: como essas instituições chegam a cidades sem grandes ofertas econômicas, de trabalho e de capital, a população local que poderia abrir negócios (serviços e comércios) para atender as demandas da nova universidade, muitas vezes não dispõe de recursos financeiros ou mesmo de conhecimento em negócios para usufruir as "benesses econômicas" trazidas pela universidade. Em muitos casos, os novos comércios e serviços demandados pelas universidades são fornecidos por empresas de fora ou por pessoas originárias de outras localidades e que abrem seus negócios na cidade, contratando a população local por baixos salários.

Já nas regiões economicamente dinâmicas, as universidades acabam participar do desenvolvimento científico e tecnológico relacionado à tipologia da cadeia produtiva local/regional. Além disso, em algumas dessas cidades, a população local não percebe grandes mudanças no cotidiano da cidade, uma vez que elas já possuíam comércios e serviços mais estruturados.

Em qualquer das situações, as universidades, além de contribuírem para o desenvolvimento educacional e cultural, acabam por se constituir grandes agentes econômicos e políticos e, consequentemente, com participação ativa no processo de 
produção do espaço urbano. Esses novos campi inserem grandes somas de recursos nas economias locais e regionais. As universidades também disponibilizam às cidades várias de suas infraestruturas e facilidades, tais como auditórios para a realização de encontros, convenções ou eventos culturais. Também ajudam a difundir a imagem da cidade e fortalecer o turismo (de eventos e visitas de familiares dos estudantes, por exemplo).

No Brasil, nós acreditamos que um dos maiores desafios urbanos na expansão das universidades é a necessidade de se considerar as implicações decorrentes da inserção de formas novas ou renovadas em um determinado espaço, bem como da chegada de novos moradores. As características da estrutura urbana e da morfologia das cidades não podem ser esquecidas, bem como os anseios, necessidades e esperanças de suas populações nas atividades específicas que aí se desenvolvem. A participação da população no processo de instalação dos campi, bem como um planejamento mais realista e temporalmente mais extenso é importante para fortalecer as instituições e suas relações com a cidade.

Finalmente, é salutar encontrarmos grandes universidades em cidades médias e pequenas, e universidades pequenas em cidades grandes. A rede urbana e a rede de ensino superior romperam os padrões e determinações das redes urbanas clássicas, bem como as universidades podem romper com a hierarquia histórica.

\section{Referências Bibliográficas}

BAUMGARTNER, W. H. Small city and new University. Perspectives and conflicts after the establishment of new public Brazilian universities in small cities. Anais do Colloque Aux frontières de l'urbain. Petites villes du monde: émergence, croissance, rôle économique et social, intégration territoriale, gouvernance. Avignon, janeiro de 2014, p. 759 -775.

CAPEL, H. La Morfología de las Ciudades. Sociedad, cultura y paisaje urbano. Barcelona: Ediciones del Serbal, 2002.

CASSIOLATO, J. E. A Economia do Conhecimento e as Novas Políticas Industriais e Tecnológicas. In: LASTRES, H. M. M \& ALBAGLI, Sarita (Org.). Informação e globalização na era do conhecimento. Rio de Janeiro: Campus, p. 164-190, 1999.

CLAVAL, P. Politics and the university. In: Wüsten, Herman van der (Edt.). The urban university and its identity. Roots, locations, roles. Dordrecht: Kluwer Academic Publishers, p. 29-46, 1998.

DEMAZIÈRE, C; BAUMGARTNER, W. H. Les universités dans les petites et moyennes villes au Brésil et en France: mise en place et effets. In: DIDIER, Paris (Org.). Vivre le territoire et faire la ville autrement? Regards croisés franco-brésiliens. Lille, 2015.

FLORIDA, R. The rise of creative class. New York: Basic Books, 2002. 
FLORIDA, R. Cities and creative class. New York: Routledge, 2005.

HENRIQUE, W. A instalação da UFRB, a ação do Programa Monumenta e o turismo étnico na reestruturação urbana e no cotidiano de Cachoeira-BA: Notas preliminares de pesquisa. Geotextos (Salvador), 2009, v. 5, p. 89-112.

. Dinâmicas urbanas e regionais em cidades médias após a instalação de universidades públicas. In: XII Seminário da Rede Iberoamericana de Pesquisadores sobre Globalização e Território, 2012, Belo Horizonte. Anais do XII Seminário da RII, 2012. v. 1. p. 1-16.

Serviços educacionais, expansão de universidades públicas e o desenvolvimento urbano e regional de cidades médias e pequenas no Brasil. In: GUTIÉREZ, J. A. et al. (Orgs.). Los Servicios: dinámicas, infraestructuras y cohesión territorial. Cáceres: Copergraf S. L., p. 197-209, 2013.

IBGE (Instituto Brasileiro de Geografia e Estatística). Censo Populacional do Brasil 2010. Disponível em: www.ibge.gov.br. Acesso em: 19 dez. 2014.

LEFEBVRE, H. De lo Rural a lo Urbano. Barcelona: Ediciones 62, 1973.

The production of space. Malden: Blackwell Publishing, 1991.

PNUD (Programa das Nações Unidas para o Desenvolvimento). Atlas do Desenvolvimento Humano no Brasil. Perfil municipal de Cachoeira/BA. Brasília, 2013. Disponível em: www.atlasbrasil.org.br/2013/perfil/cachoeira_ba. Acesso em: 19 dez. 2013.

SANTANA, E. T. de. A Universidade Federal do Recôncavo da Bahia e a Produção do Espaço Urbano-Regional. Dissertação. Programa de Pós-graduação em Geografia. Universidade Federal da Bahia. 2012.

SANTOS, M. A urbanização brasileira. 5. ed. São Paulo: Edusp, 2005.

SPOSITO, M. E. B. O chão em pedaços: urbanização, economia e cidades no Estado de São Paulo. Tese (Livre Docência). UNESP/ Presidente Prudente. 2004.

UFOB (Universidade do Oeste da Bahia). Relatório de gestão do exercício de 2014. Barreiras: UFOB, 2015. Disponível em: http://www.ufob.edu.br/index.php/a-ufob/documentos/relatorios-de-gestao?download=973:relatorio-de-gestao-2014. Acesso em: 6 out. 2015.

UFRB (Universidade Federal do Recôncavo da Bahia). UFRB em números. Cruz das Almas: UFRB, 2013. Disponível em: http://www.ufrb.edu.br/proplan/images/numeros/ UFRB_em_Nmeros_2013.pdf; Acesso em: 29 jul. 2014. 
WUSTEN, H. van der. A warehouse of precious goods. The university in its urban context. In: WÜSTEN, Herman van der (Edt.). The urban university and its identity. Roots, locations, roles. Dordrecht: Kluwer Academic Publishers, p.1-13, 1998.

ZECHER, S. E. The economic role of universities in medium-sized cities: a case study of the Medical College of Georgia in Augusta, Georgia. Dissertação. Mestrado em Ciência em Política Pública. Instituto de Tecnologia da Geórgia. 2005.

\section{Agradecimentos}

Ao CNPq pelo apoio financeiro a nosso projeto de pesquisa.

Recebido em: 17/9/2015 Aceito em: 7/10/2015

\footnotetext{
1 As questões referentes a instalação da UFRB em Santo Amaro e as movimentações políticas e sociais na disputa entre cidades da Bahia para recebimento de um campus de universidade federal estão sendo trabalhadas, respectivamente, nos projetos doutoramento de Shanti Nitya Marengo e Elissandro Trindade de Santana, do PPGGeo/UFBA.

${ }^{2}$ Financiamento CAPES.

${ }^{3}$ Para compreender a definição de cidades médias e pequenas na Europa indicamos as publicações do grupo de pesquisa ESPON, em especial, o Atlas 2014 "Mapping European Territorial Structuresand Dynamics", disponível em http://atlas.espon.eu/.

${ }^{4}$ A Unesp realiza desde 1996 um estudo sobre o impacto econômico de seus campi no interior de São Paulo. No estudo de 2013, disponível em https://ape.unesp.br/pdf_siteape/TextoPesquisa.pdf, apresenta, entre diversos indicadores, que o retorno de ICMS para o município de Botucatu foi de $\mathrm{R} \$ 72,5$ milhões e para o campus da Unesp na cidade de $\mathrm{R} \$ 308,3$ milhões.

${ }^{5} \mathrm{Na}$ então Alemanha Ocidental, ao final dos anos 1970, várias universidades foram instaladas nas fronteiras com a antiga Tchecoslováquia e Alemanha Oriental, para criarem empregos e fortalecer a economia local e regional, favorecendo a manutenção/ampliação dos contingentes populacionais nessas áreas estratégicas e que vinham sendo esvaziadas devido à falta de perspectivas econômicas, como por exemplo as Universidade de Passau e de Regenburg.

${ }^{6} \mathrm{O}$ trabalho de Fritz Machlup The production and distribution of knowledge in the United States (Princeton University Press, 1962), é considerado o pioneiro na discussão da economia do conhecimento.

${ }^{7}$ Essa não é associação nova e fazemos referência às universidades/institutos tecnológicos alemães criados no século XIX como suporte para o processo de industrialização daquele país, conforme pode ser observado nos diversos capítulos da obra The history of the university in Europe, volume III, editada por Walter Rüeg (Cambridge University Press, 2004).

${ }^{8}$ Um exemplo desse fato em nossa pesquisa está na cidade de Cachoeira (BA), onde a classe política e os moradores não compreendem o sentido da existência de um curso superior de cinema ou de museologia na cidade. Segundo a população local, esses cursos só atraem estudantes "festeiros" e afirma que seria melhor para a cidade ter um curso de direito.

${ }^{9}$ Os dados são do sistema de registro dos cursos de graduação, disponíveis na plataforma e-Mec (emec.gov.br) e cabe destacar que alguns municípios mapeados tiveram cursos presenciais temporários. Essa base de dados, mesmo sendo elaborada pelo próprio Ministério da Educação, apresenta algumas lacunas, principalmente ao período de funcionamento de cursos temporários e aos cursos que foram extintos.
} 
${ }^{10}$ Compreendemos a produção do espaço a partir das contribuições de Lefebvre (1991). A produção do espaço envolve questões econômicas e técnicas, mas também se amplia, pois o espaço é também espaço político e estratégico (incluindo reserva de espaços). Lefebvre (1991), ainda destaca que devemos nos pautar em uma unidade nos níveis de análise, articulando as forças de produção e seus componentes (natureza, trabalho, tecnologia e conhecimento), as estruturas (relações de propriedade) e as superestruturas (instituições e o Estado).

11 Para Lefebvre (1973, p. 140/141), "la ciudad proyecta sobre el terreno una sociedad, una totalidad social o una sociedad considerada como totalidad, comprendida su cultura, instituciones, ética, valores, en resumen sus supraestructuras, incluyendo su base económica y las relaciones sociales que constituyen su estructura propiamente dicha. (...) en la ciudad se materializan, se encarnan en obras, obras que, como fácilmente se comprende, son los monumentos, edificios públicos y privados, en los cuales y a través de los cuales la sociedad global se presenta o se representa; muy frecuentemente constituyen símbolos".

${ }^{12}$ Esta vinculação entre cursos de origem de estudantes, renda e locais de moradia nas cidades foi objeto de estudo de nossa pesquisa de Pós-doutorado realizada na Alemanha, entre 2010 e 2011 (Henrique, 2009; Henrique 2012; Baumgartner, 2014). Através de mapeamentos realizados, identificamos, por exemplo, que os estudantes dos cursos de Administração, Economia e Direito da Universidade de Passau residiam nas áreas mais valorizadas da cidade, especialmente no distrito histórico, onde o valor dos aluguéis eram superiores aos dos bairros mais periféricos.

${ }^{13}$ Cachoeira, segundo o censo populacional do IBGE (2010), possui 32.026 habitantes. Segundo do PNUD (2013), entre sua população, 16,7\% são extremamente pobres e 33,8\% são pobres. 
